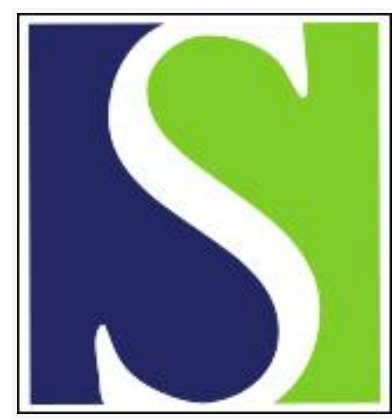

Scand J Work Environ Health 2007;33(1):37-44

https://doi.org/10.5271/sjweh.1062

Issue date: 31 Feb 2007

Distinguishing between overtime work and long workhours among full-time and part-time workers

by Beckers DGJ, van der Linden D, Smulders PGW, Kompier MAJ, Taris TW, Van Yperen NW

Affiliation: Department of Work and Organizational Psychology, Behavioural Science Institute, Radboud University Nijmegen, PO Box 9104, NL-6500 HE Nijmegen, Netherlands. d.beckers@psych.ru.nl

Refers to the following texts of the Journal: 2003;29(3):171-188 2005;31(6):405-408 2003;29(1):1-4 2005;31(5):329-335

The following articles refer to this text: 2008;34(3):213-223; 0;0 Special issue: 0

Key terms: fatigue; full-time worker; job characteristics; long workhours; overtime; part-time worker; work motivation

This article in PubMed: www.ncbi.nlm.nih.gov/pubmed/17353963 


\title{
Distinguishing between overtime work and long workhours among full-time and part-time workers
}

\author{
by Debby GJ Beckers, MA, ${ }^{1}$ Dimitri van der Linden, PhD, ${ }^{1}$ Peter GW Smulders, PhD, ${ }^{2}$ Michiel AJ Kom- \\ pier, PhD, ${ }^{1}$ Toon W Taris, PhD, ${ }^{1}$ Nico W Van Yperen, $P h D^{3}$
}

\begin{abstract}
Beckers DGJ, van der Linden D, Smulders PGW, Kompier MAJ, Taris TW, Van Yperen NW. Distinguishing between overtime work and long workhours among full-time and part-time workers. Scand $J$ Work Environ Health 2007;33(1):37-44.
\end{abstract}

Objectives This study aimed at disentangling the effects of overtime hours from those of long workhours. For part-time workers, overtime work is not intertwined with long workhours as it is for full-time workers. Therefore, part-time and full-time employees were compared with regard to the association between overtime and well-being (fatigue and work motivation). Such comparisons may also shed more light on the psychological meaning of overtime work for part-time and full-time workers.

Methods A survey study was conducted among a representative sample of Dutch employees $(\mathrm{N}=2419)$. An analysis of covariance was used to investigate whether the relationship between overtime and well-being differs between marginal part-time (8-20 contractual workhours), substantial part-time (21-34 hours), and full-time ( $\geq 35$ hours) workers. Work characteristics (ie, job demands, decision latitude, and job variety), age, and gender were treated as covariates.

Results No significant relationship between overtime and fatigue was found for any of the contract-hour groups. For the part-time workers, overtime was not related to higher work motivation, whereas for full-time workers it was.

Conclusions It is important to distinguish between overtime and long workhours, given the differential overtime-motivation relationship among part-time and full-time workers. This finding suggests that part-time employees work overtime for reasons other than motivation or that working overtime does not enhance work motivation for this group of employees. Overtime work seems to have a different meaning for part-time and full-time workers.

Key terms fatigue; job characteristics; work motivation.

In studies on the health effects of overtime work, the concepts of long workhours and overtime have often been used interchangeably (1-4). One should realize, however, that although these concepts are indeed intertwined, they are not identical. Long workhours can be defined as workhours that exceed the standard full-time workweek, whereas overtime refers to workhours that exceed the number of contractual hours. Accordingly, long workhours by definition imply a certain number of overtime hours, but the reverse is not always true since employees with a part-time contract may also work overtime.

To our knowledge, an explicit distinction has not yet been properly made between long workhours and overtime work in the literature. Research on prolonged worktime has been mainly directed towards full-time employees (3, 5-13). For these employees, it is impossible to distinguish between the effects of long workhours and the effects of pure overtime, as for full-timers overtime work and long workhours go hand in hand.

The relatively strong focus on long workhours and full-timers in previous research on overtime work is understandable since it is often assumed that the relationship between overtime and health problems arises from too much effort and too little time to recover (12). [See, for example, the effort-recovery model of Meijman \& Mulder (14).] It has been shown that chronic insufficient recovery may disturb psychophysiological

1 Radboud University Nijmegen, Behavioural Science Institute, Nijmegen, Netherlands.

2 TNO Work and Employment, Hoofddorp, Netherlands.

3 University of Groningen, Groningen, Netherlands.

Reprint requests to: D Beckers, Department of Work and Organizational Psychology, Behavioural Science Institute, Radboud University Nijmegen, PO Box 9104, NL-6500 HE Nijmegen, Netherlands. [E-mail: d.beckers@psych.ru.nl] 
processes and may eventually lead to health problems $(15,16)$. For full-time employees, overtime work may, therefore, be a problem of too much exposure to work demands combined with too little recovery.

The aim of this study was to distinguish between the potential effects of overtime work and those of long workhours. One way to separate the effects of overtime hours from those of long workhours is to take part-time employees into account. For part-time workers, overtime work also implies more exposure to work demands (more effort expenditure), but not necessarily too much exposure or too little recovery. As overtime and long workhours do not overlap for this group of employees, including them in a study allows for a more valid assessment of the effects of "pure overtime". If our results show a difference in the overtime-wellbeing associations between full-time and part-time workers, we would have empirical evidence to support our assumption that it is important to acknowledge the difference between long workhours and overtime work and to include part-time workers in future overtime studies. Furthermore, a different overtime-well-being association for part-time and full-time workers indicates that the psychological meaning of overtime may differ for both groups.

Based on these theoretical considerations, the research question of this study is "What are the associations between overtime and well-being among part-time employees, and do these associations differ from those of full-time employees?" To strengthen the design of the study, not only a negative indicator of well-being (fatigue), but also a positive indicator was included, namely, work motivation. By doing so, we acknowledge that (overtime) work does not necessarily have to be related to negative consequences but may also be studied from a work motivational perspective (17).

Previous research has shown that the psychosocial work environment differs for part-time and full-time employees. Part-time employment is more widespread in the lowest occupational status categories that entail jobs that are typically more monotonous and that offer fewer opportunities for career development and lower payment rates (18). Psychosocial work characteristics have, in turn, often been found to be related to wellbeing independently of workhours. For example, there are numerous studies showing that high demands are associated with high levels of stress and fatigue (19, 20). Finally, work characteristics also show associations with overtime hours [eg, job demands are moderately associated with working overtime $(5,13)]$. Therefore, in this study, we statistically controlled for the influence of three central work characteristics (ie, job demands, decision latitude, and job variety). Controlling for work characteristics allows for a more valid assessment of the effects of overtime as the possible confounding effects of work characteristics are ruled out.

In the European Union, part-time work is mainly a female phenomenon (32\% of women versus $6 \%$ of men work part-time) (21). In the Netherlands, $72 \%$ of female employees works part-time, as opposed to $21 \%$ of their male colleagues (22). Part-time employment is also particularly prevalent at the beginning and at the end of people's work careers (ie, among young and old employees), whereas full-time employment is common in the years in between (18). As former studies have shown that full-time and part-time workers differ with respect to age and gender, we also statistically controlled for these characteristics in our study. Potential differences between full-time and part-time workers with respect to the overtime-well-being relationship can therefore not be attributed to these personal characteristics.

\section{Stuy population and methods}

\section{Study population and procedures}

Data were collected in 2002 as part of a large questionnaire study on the work situation of Dutch employees (23). ${ }^{4}$ A total of 3093 Dutch workers completed questions about contractual workhours and overtime hours. [See "Measures".] Self-employed men and women were excluded as the question on contractual workhours would not apply to them. Only employees who reported less than 41 contractual workhours and less than 40 overtime hours a week were included in our study $(\mathrm{N}=2653)$. This selection assured enough variance with respect to overtime and contractual hours.

Furthermore, preliminary inspection of our data revealed that some respondents reported equal numbers of contractual and overtime hours (eg, 40 contractual hours and 40 overtime hours, 38 contractual hours and 38 overtime hours, and so on). This result suggested that these respondents misunderstood the overtime question. Therefore, we only included employees whose number of overtime hours differed from their contractual hours. Ultimately, the final sample consisted of 2419 employees (59.7\% men, $40.3 \%$ women) who ranged in age from 15 to 67 (mean 39.7, SD 11.8) years. The respondents worked an average of 31.7 (SD 10.0) hours on contract self-employed workers. 
and spent an average of 3.5 (SD 6.0) hours a week on overtime work. The sample can be considered to be representative of the Dutch working population in terms of age, gender, and number of part-time and full-time employees (24).

\section{Measures}

Contractual workhours were measured with the following item: "How many hours a week do you work on contract?" Based on the classifications of the European Foundation for the Improvement of Living and Working Conditions (25), the following three subgroups were created: a marginal part-time contract-hours group (8-20 weekly contractual workhours; $\mathrm{N}=382$ ), a substantial part-time contract-hours group (21-34 weekly contractual workhours; $\mathrm{N}=518$ ), and a (close to) fulltime contract-hours group ( $\geq 35$ contractual workhours; $\mathrm{N}=1451)$.

Overtime hours were measured with the following item: "On average, how many hours a week do you work overtime? (paid AND unpaid overtime work; include work you execute at home; DO NOT include your commuting time)". Respondents who did not work overtime were assigned to a "no overtime group" ( $\mathrm{N}=926)$, respondents with 1 to 5 overtime hours a week were assigned to a "low overtime group" ( $\mathrm{N}=1061)$, and respondents whose overtime exceeded 5 hours a week were assigned to a "high overtime group" ( $\mathrm{N}=432)$.

Fatigue was assessed with the five-item exhaustion scale from the Dutch version of the Maslach Burnout Inventory (General Survey) (26). A sample item is "My work makes me feel mentally exhausted" ( $1=$ "never", 7 = "every day"). Cronbach's $\alpha$ was 0.90 . Reference scores were provided by Schaufeli \& van Dierendonck (26).

Work motivation was assessed with ten items derived from the work-engagement scale (27). Typical items are "When I get up in the morning, I am motivated to go to work" and "I am enthusiastic about my work". The items were scored on a five-point scale ( 1 = "hardly ever", $5=$ "always"). Cronbach's $\alpha$ was 0.92 .

Three major work characteristics were assessed using the Job Content Questionnaire (28). Job demands were measured with five items. One sample question is "Do you have to work very hard?" Cronbach's $\alpha$ was 0.83 . Job variety was measured with the 5 -item skill discretion scale of the questionnaire, for example, "Do you get to do a variety of different things on your job?" Cronbach's $\alpha$ was 0.79 . Decision latitude was measured using five items. An exemplary question is "Do you have the freedom to decide how to do your job?" Cronbach's $\alpha$ was 0.84 . The scores of the items of these three scales ranged from 1 ("never") to 4 ("always"). Higher scores on these scales indicated a higher (quantitative) workload, more job variety, and more decision latitude.

\section{Statistical analyses}

An analysis of covariance (ANCOVA) was used to examine whether part-time and full-time workers differed with respect to the overtime-fatigue association and the overtime-motivation association. The overtime group (no, low, high) and contract-hours group (marginal parttime, substantial part-time, full-time) were entered as independent variables, and fatigue and work motivation were treated as dependent variables. In these analyses, the contract type dimension (three levels) was combined with the overtime dimension (three levels). This combination resulted in the following nine subgroups: (i) the no overtime-marginal part-time contract group $(\mathrm{N}=202)$; (ii) no overtime-substantial part-time contract group ( $\mathrm{N}=197)$; (iii) no overtime-full-time contract group ( $\mathrm{N}=486$ ); (iv) low overtime-marginal part-time contract group ( $\mathrm{N}=122)$; (v) low overtime-substantial part-time contract group ( $\mathrm{N}=234)$; (vi) low overtime-full-time contract group ( $\mathrm{N}=692)$; (vii) high overtime-marginal part-time contract group ( $\mathrm{N}=58$ ); (viii) high overtimesubstantial part-time contract group ( $\mathrm{N}=87$ ); and (ix) high overtime-full-time contract group ( $\mathrm{N}=273)$. By comparing these nine overtime-contract groups using an ANCOVA (overtime group $\times$ contract hours group), we examined whether the relationship between overtime on one hand and fatigue and work motivation on the other differed for part-time and full-time workers.

As discussed earlier, in our analyses, we controlled for work characteristics (ie, job demands, decision latitude, and job variety), age, and gender. Potential differences between full-time and part-time workers with respect to the link between overtime and well-being can not, therefore, be attributed to these work and personal characteristics.

\section{Results}

\section{Description of the research sample}

Appendix 1 presents descriptive statistics (means, standard deviations, and correlations) of the variables under study.

In our sample, $61.7 \%$ of the employees reported working overtime. The data revealed that extreme overwork occurred rarely as $81.4 \%$ of the overtime workers reported working less than 10 overtime hours a week. Only $2.1 \%(\mathrm{~N}=51)$ of all 2419 of the respondents 
Table 1. Differences between the marginal part-time group, the substantial part-time group, and the full-time group with respect to overtime, work characteristics, and personal characteristics. (SD = standard deviation)

\begin{tabular}{|c|c|c|c|c|c|c|c|c|c|c|}
\hline & \multicolumn{9}{|c|}{ Contract group } & \multirow{3}{*}{$\begin{array}{l}\text { Multivariate } \\
F(14,4612)=20.30 \\
P<0.001 ; \text { univariate } \\
F(2,2312)\end{array}$} \\
\hline & \multicolumn{3}{|c|}{$\begin{array}{l}\text { Marginal part-time } \\
\quad(\mathrm{N}=382)\end{array}$} & \multicolumn{3}{|c|}{$\begin{array}{l}\text { Substantial part-time } \\
\qquad(\mathrm{N}=518)\end{array}$} & \multicolumn{3}{|c|}{$\begin{array}{l}\text { Full-time } \\
(\mathrm{N}=1451)\end{array}$} & \\
\hline & Mean & SD & $\%$ & Mean & SD & $\%$ & Mean & SD & $\%$ & \\
\hline Prevalence of overtime work & . & . & $47^{\mathrm{b}, \mathrm{c}}$ & . & . & $62^{\mathrm{a}}$ & . & . & $67^{\mathrm{a}}$ & $\begin{array}{l}\chi^{2}(\mathrm{df}=2, \mathrm{~N}=2351)= \\
48.45, \mathrm{P}<0.001\end{array}$ \\
\hline Overtime (range 0-39 hours) & 3.42 & 6.77 & . & 3.81 & 7.59 & . & 3.43 & 5.02 & . & $0.81, P=0.44$ \\
\hline Overtime $>0$ (range 1-39 hours) & $7.26^{c}$ & 8.34 & . & 6.14 & 8.86 & . & $5.16^{\mathrm{a}}$ & 5.39 & . & $8.69, P<0.001$ \\
\hline Job demands (range 1-4) & $2.27^{b, c}$ & 0.56 & . & $2.53^{\mathrm{a}}$ & 0.60 & . & $2.50^{\mathrm{a}}$ & 0.57 & . & $26.24, P<0.001$ \\
\hline Decision latitude (range 1-4) & $2.69^{b, c}$ & 0.71 & . & $2.89^{a}$ & 0.54 & . & $2.91^{\mathrm{a}}$ & 0.60 & . & $20.35, P<0.001$ \\
\hline Job variety (range 1-4) & $2.64^{b, c}$ & 0.66 & . & $2.97^{\mathrm{a}}$ & 0.51 & . & $3.01^{\mathrm{a}}$ & 0.52 & . & $70.14, P<0.001$ \\
\hline Age (range $15-67$ years) & $34.9^{b, c}$ & 13.9 & . & $40.6^{a}$ & 10.8 & . & $41.6^{a}$ & 10.5 & . & $53.57, P<0.001$ \\
\hline Gender & & & & & & & & & & $\begin{array}{l}\chi^{2}(d f=2, N=2351)= \\
667.67, P<0.001\end{array}$ \\
\hline Male & . & . & $22^{b, c}$ & . & . & $31^{a, c}$ & . & . & $81^{\mathrm{a}, \mathrm{b}}$ & \\
\hline Female & . & . & 78 & . & . & 69 & . & . & 19 & \\
\hline
\end{tabular}

a Differs significantly from the respective value of the marginal part-time group.

${ }^{b}$ Differs significantly from the respective value of the substantial part-time group.

c Differs significantly from the respective value of the full-time group.

Table 2. Associations between overtime and contract on one hand and work-related well-being (fatigue and work motivation) on the other (covariates included).

\begin{tabular}{ll}
\hline Factor & Univariate \\
\hline Overtime & \\
Fatigue & $\mathrm{F}(2,2301)=0.52 ; \mathrm{P}=0.60$ \\
$\quad$ Work motivation & $\mathrm{F}(2,2295)=1.75 ; \mathrm{P}=0.17$ \\
Contract & \\
$\quad$ Fatigue & $\mathrm{F}(2,2301)=2.08 ; \mathrm{P}=0.13$ \\
$\quad$ Work motivation & $\mathrm{F}(2,2295)=1.34 ; \mathrm{P}=0.26$ \\
$\begin{array}{l}\text { Overtime } \times \text { contract } \\
\text { Fatigue }\end{array}$ & $\mathrm{F}(4,2301)=1.59 ; \mathrm{P}=0.17$ \\
Work motivation & $\mathrm{F}(4,2295)=6.02 ; \mathrm{P}<0.001$ \\
\hline
\end{tabular}

reported working 20-29 overtime hours, and only $1.8 \%$ ( $\mathrm{N}=44$ ) reported working 30-39 overtime hours. Most of the overtime workers $(71.1 \%)$ reported working 1-5 overtime hours a week.

Overtime work was prevalent within all three contract groups. Table 1 shows that the percentage of employees working overtime was lowest among the marginal part-time workers.

As also shown in table 1, the three contract groups did not differ with respect to the weekly number of overtime hours. However, once working overtime (overtime $>0$ ), the marginal part-time workers reported a significantly higher number of overtime hours than the full-time workers who worked overtime $(\mathrm{P}<0.001)$ (table 1).

Analyses of variance revealed that the marginal parttime group reported significantly lower job demands, but also less decision latitude and less job variety than both of the other contract groups $(\mathrm{P}<0.001)$ (table 1). In terms of Karasek's demand-control model, this profile can be characterized as "passive" (29). The substantial part-time group and full-time group did not differ significantly with respect to this set of work characteristics $(\mathrm{P}>0.05)$. This finding implies that it was the full-time workers and the substantial part-time workers rather than the two part-time groups that had more or less similar work conditions.

Finally, the marginal part-time group was significantly younger than the substantial part-time and fulltime groups $(\mathrm{P}<0.001)$, whereas the latter two groups did not differ significantly with respect to age $(\mathrm{P}=0.19)$. The marginal part-time group had the largest proportion of women, and the full-time group had the smallest proportion (table 1). In both part-time groups, most of the employees were women, whereas the full-time group consisted largely of men.

\section{Comparison of part-time and full-time workers with respect to the overtime-well-being association}

When compared with the norm scores, the average fatigue level of all of the overtime and contract groups was moderate (26). The interaction between overtime group and contract type was not statistically significant for fatigue (table 2). Accordingly, there is no reason to believe that the association between overtime and fatigue differs for part-time and full-time workers. At the same time, the analyses revealed that none of the overtime groups differed with respect to fatigue $\left(\mathrm{M}_{\text {no overtime group }}=\right.$ $2.69, \mathrm{M}_{\text {low overtime group }}=2.68$, and $\mathrm{M}_{\text {high overtime group }}=2.78$ ), nor did the contract groups differ with respect to fatigue 


\section{Work motivation}

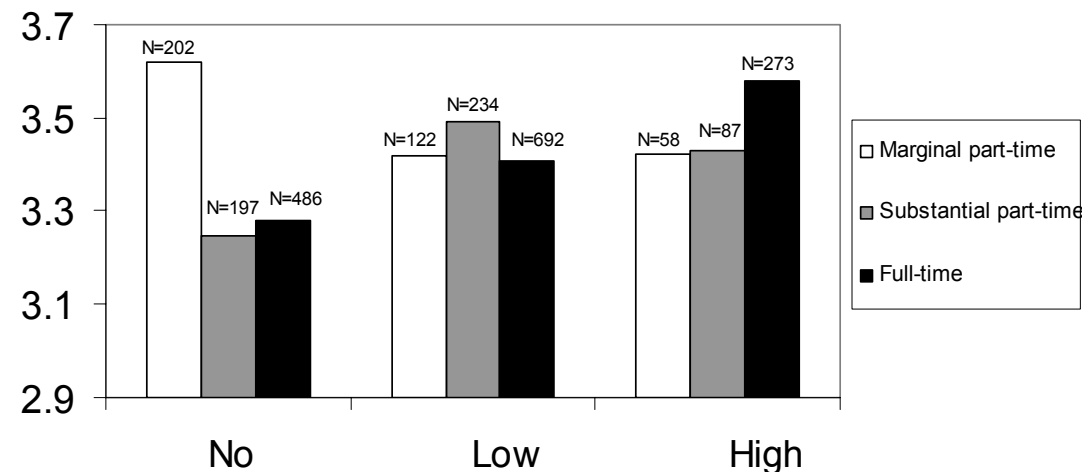

Overtime work
Figure 1. Pattern of overtime $\times$ contract interaction on work motivation. Gender, age, job demands, decision latitude, and job variety were included as covariates.
$\left(\mathrm{M}_{\text {marginal part-time group }}=2.61, \mathrm{M}_{\text {substantial part-time group }}=2.83\right.$, and $\mathrm{M}_{\text {full-time group }}=2.71$ ). Therefore, fatigue was not related to the number of overtime hours or to contractual workhours.

As regards work motivation, we found a significant interaction between overtime and contract type (table 2 and figure 1). This finding implies that the relationship between overtime and work-motivation is not the same for the three contract groups.

For the full-time employees, work motivation increased linearly with increasing overtime. All of the overtime groups differed significantly from each other $(\mathrm{P}<0.01)$, the high overtime group reporting the highest work motivation and the no overtime group having the least work motivation. [See the paper by Beckers et al (5)]. We did not find such a positive linear relationship for the two part-time groups (figure 1). Especially the marginal part-time group showed a different overtime-motivation pattern, the marginal part-time workers without overtime being the most motivated. Within the substantial part-time group, we also did not find a positive linear relationship between overtime and motivation. The substantial part-time workers with high overtime were not more motivated than the substantial part-timers with low or no overtime work $(\mathrm{P}=0.42$ and $\mathrm{P}=0.06$, respectively).

\section{Discussion}

It has been insufficiently acknowledged in the literature that the concepts of long workhours and overtime work are not identical, although intertwined. One way to disentangle the effects of overtime from those of long workhours is to study part-time employees (distinguishing between those who do and those who do not work overtime) and to compare these part-time workers to full-time workers (who do and do not work overtime). Such comparisons may shed more light on the psychological meaning of overtime work (ie, on the associations between overtime and fatigue and between overtime and work motivation).

In the absence of a significant overtime-contract group interaction with respect to fatigue, there is no reason to conclude that the association between overtime and fatigue differs for part-time and full-time workers. In our study sample, neither overtime work nor contractual workhours seemed to be related to fatigue, which is the case for both part-time and full-time workers. According to the results of this study, it seems that a strict distinction between long workhours and overtime work is not necessary when fatigue is being investigated, as neither more overtime hours nor long workhours were related to greater fatigue. It is important to note that former studies on overtime did report an association between overtime and fatigue (12). These contradictory findings can be understood when the number of overtime hours in the current study is taken into consideration. Most of our respondents reported moderate overtime hours (ie, 1-5 hours) and extreme overtime work was scarce. On the basis of our findings, we therefore concluded that moderate overtime work was not related to fatigue. As former studies on overtime work often studied the consequences of extreme overtime work (12), this difference may explain why, in these studies, overtime work was related to fatigue (and other health problems), whereas in our study it was not.

The significant interaction between overtime and contract type on work motivation found in our study indicates that the relationship between overtime and work motivation differs for part-time and full-time workers. Whereas, for full-time workers, more overtime was linearly related to work motivation, this was not the case for the part-time groups. This finding indicates that it is indeed important to disentangle overtime work from 
long workhours. Exclusive attention to long workhours (ie, overtime work among full-time employees) would have prevented us from noticing the differential relationship between overtime and work motivation for part-time and full-time workers. For full-time workers, a higher number of overtime hours was accompanied by higher levels of work motivation. This finding suggests that full-time employees who work overtime are "happy" (motivated) employees (5). For part-time workers, this relationship was less straightforward as many overtime hours did not coincide with higher work motivation. This finding suggests that (especially marginal) part-time workers work overtime for reasons other than motivation and that overtime work seems to have a different meaning for part-time and full-time workers. One might speculate that the psychosocial profile of overtime work differs for part-time and full-time employees. It may be that part-time employees as a group often work overtime involuntarily (obligatory overtime work) or that extra pay is their main reason for working overtime. It would be informative if future studies would elucidate this matter further by taking into account the reasons why part-time and full-time workers work overtime.

\section{Study limitations}

Although informative, our study also had some limitations. First, it is a "self-report only" study, and therefore one might argue that common method variance could have inflated the associations between our study variables (30). However, in his recent article, Spector (30) stated that "the popular position suggesting that common method variance automatically affects variables measured with the same method is a distortion and oversimplification of the true state of affairs, reaching the status of urban legend [p 221]" (30). Spector argued that this common method variance concept has little explanatory power, and he suggested that potential specific biases such as social desirability, negative affectivity, and acquiescence be investigated. His study revealed that the distorting effects of these biases are often limited. This finding may imply that self-report measures can be considered to be a useful and valid method when the associations between variables are studied (31).

It would be preferable in overtime research to also include a more "objective" assessment of the number of overtime hours and contractual hours (eg, through administrative company files), as, for some respondents, a correct assessment of their average weekly overtime hours may be difficult. However, more objective measurements may also incorporate some limitations (32). In overtime research, we seem to face two somewhat competing study demands. First we want large, representative, and heterogeneous study samples, and, second, we could recommend the inclusion of individualized company data, which imposes complications as to logistics and data collection and to privacy legislation (eg, selective participation). Furthermore, company records of overtime work only reveal the formally registered overtime hours. In many cases, however, overtime hours are not registered, and, therefore, only concentrating on administrative company files would result in an underestimation of the prevalence of overtime work. A partial way out of this dilemma may be to ask very clear and factual questions when data regarding overtime hours are collected. Most importantly, it should be clear to respondents whether the question on workhours concerns overtime hours, contractual workhours, or total workhours.

In this study, we constructed three overtime groups, the no overtime group, the low overtime group (15 overtime hours a week), and the high overtime group ( $>5$ overtime hours a week). This classification is somewhat arbitrary, especially with respect to the high overtime group, which showed much variance. To test whether our cut-off points influenced our findings, we conducted posthoc analyses in which we subdivided the high overtime group into two groups [eg, high overtime (6-10 hours) and very high overtime (>10 hours)]. If these groups had differed with respect to well-being, it would have been better to include both a high overtime group and a very high overtime group in our study. Our analyses, however, showed that these two groups did not differ significantly with respect to fatigue $(\mathrm{P}=0.97$, $\mathrm{M}_{\text {high overtime }}=2.80$ and $\mathrm{M}_{\text {very high overtime }}=2.74$ ) nor with respect to work motivation $\left(\mathrm{P}=0.33 ; \mathrm{M}_{\text {high overtime }}=3.67\right.$ and $\mathrm{M}_{\text {very high overtime }}=3.53$ ). Therefore, it is unlikely that the results of our study depended on our choice of overtime cut-off points.

Another limitation is the cross-sectional nature of our study, which implies that no causal inferences can be made. The extent to which work motivation precedes or follows decisions about contract type and overtime is unclear, for example. This is a complex issue, and we believe that causal relationships between variables such as contract type, overtime work, work characteristics, and well-being are dynamic and reciprocal rather than simple and one-directional. Through stronger designs (ie, using longitudinal, quasi-experimental, and intervention studies) future research may elucidate these dynamic processes $(33,34)$.

In this study, we took into account three major characteristics of the psychosocial (overtime) work environment of the (overtime) worker. However, this conceptualization of the quality of (overtime) work may still be rather global. From a work psychological perspective, it is therefore preferable that future studies pay more attention to (i) motives for working overtime (voluntary, involuntary), (ii) rewards for working overtime (eg, financial, promotional prospects), and (iii) specific work 
activities during overtime. From a work psychological perspective, especially this last aspect seems intriguing, as, thus far, surprisingly few data are available on what overtime workers actually do when they work overtime. For example, we do not know the extent to which they carry out similar or different activities (eg, more demanding or more motivating) during their overtime hours, compared with their contractual workhours. Furthermore, from this study, it follows that it is preferable to distinguish between subgroups of employees with different contract types (full-time work, part-time work). Painting a more fine-grained psychosocial profile of the overtime work of these subgroups may lead to greater insight as to why the psychological meaning of overtime seems to differ for full-time and part-time employees.

\section{Practical implications}

From our study it follows that there is no reason to examine overtime work exclusively from the perspective of protecting workers from adverse effects. Our research suggests that overtime should not be conceptualized as a phenomenon which by definition has negative implications for health and well-being. It appears that, at least in the Netherlands, many employees who work overtime are motivated, nonfatigued workers. With respect to the acceptability of overtime work, a caveat is however justified. In our study extreme overwork occurred only seldom. In the literature, there is convincing evidence that extreme overtime work [often defined as "working more than 60 hours a week" (7)] contributes to reduced well-being and health $(1,35-37)$.

All in all, the relationship between (moderate) overtime work and well-being is complex, but intriguing. Hopefully, this study will increase the awareness of the difference between overtime work and long workhours and of the possibly differential psychological meaning of overtime work for part-time and full-time workers.

\section{References}

1. Kawakami N, Haratani T. Epidemiology of job stress and health in Japan: review of current evidence and future direction. Ind Health. 1999;37:174-86.

2. Nakanishi N, Yoshida H, Nagano K, Kawashimo H, Nakamura $\mathrm{K}$, Tatara K. Long working hours and risk for hypertension in Japanese male white collar workers. J Epidemiol Community Health. 2001;55:316-22.

3. Park J, Kim Y, Cho Y, Woo K-H, Chung HK, Iwasaki K, et al. Regular overtime and cardiovascular functions. Ind Health. 2001;39:244-9.

4. Spurgeon A, Harrington JM, Cooper CL. Health and safety problems associated with long working hours: a review of the current position. Occup Environ Med. 1997;54:367-75.

5. Beckers DGJ, Van der Linden D, Smulders PGW, Kompier
MAJ, Van Veldhoven MJPM, Van Yperen NW. Working overtime hours: relations with fatigue, work motivation, and the quality of work. J Occup Environ Med. 2004;46:1282-9.

6. Nakamura K, Shimai S, Kikuchi S, Takahashi H, Tanaka $\mathrm{M}$, Nakano S, et al. Increases in body mass index and waist circumference as outcomes of working overtime. Occup Med. 1998;48:169-73.

7. Park J, Kim Y, Chung HK, Hisanaga N. Long working hours and subjective fatigue symptoms. Ind Health. 2001;39:250-4.

8. Rau R, Triemer A. Overtime in relation to blood pressure and mood during work, leisure, and night time. Soc Indic Res. 2004;67:51-73.

9. Shields M. Long working hours and health. Health Rep. 1999;11:33-48.

10. Sparks K, Cooper C, Fried Y, Shirom A. The effects of hours of work on health: a meta-analytic review. J Occup Org Psychol. 1997;70:391-408.

11. van der Hulst M, Geurts S. Associations between overtime and psychological health in high and low reward jobs. Work Stress. 2001;15:227-40.

12. van der Hulst M. Long workhours and health [review]. Scand J Work Environ Health. 2003;29(3):171-88.

13. van der Hulst M, van Veldhoven M, Beckers D. Overtime and need for recovery in relation to job demands and job control. $\mathrm{J}$ Occup Health. 2006;48:11-9.

14. Meijman TF, Mulder G. Psychological aspects of workload. In: Drenth PJD, Thierry H, de Wolff CJ, editors. Handbook of work and organizational psychology. 2nd ed. Hove (UK): Psychology Press/Erlbaum, Taylor \& Francis; 1998. p 5-33.

15. Kompier M. Arbeid en gezondheid van stadsbuschauffeurs [Work and Health among city bus drivers]. Delft (Netherlands): Eburon; 1988.

16. Sluiter JK, van der Beek AJ, Frings-Dresen MHW. The influence of work characteristics on the need for recovery and experienced health: a study on coach drivers. Ergonomics. 1999;42:573-83.

17. Van Yperen NW, Hagedoorn M. Do high job demands increase intrinsic motivation or job strain or both?: the role of job control and social support. Acad Manage J. 2003;46:339-48.

18. European Foundation for the Improvement of Living and Working Conditions (EFILWC). Part-time work in Europe. Dublin (Ireland): EFILWC; 2003.

19. van der Doef MP, Maes S. The Job Demand-Control-Support Model and psychological well-being: review of 20 years of empirical research. Work Stress. 1999;13:87-114.

20. De Lange AH, Taris TW, Kompier MAJ Houtman ILD, Bongers PM. The very best of the millennium: longitudinal research on the Demand-Control (Support) Model. J Occup Health Psychol. 2003;8:282-305.

21. Merllié D, Paoli P. Ten years of working conditions in the European Union. Dublin: European Foundation for the Improvement of Living and Working Conditions; 2001. p 1-11.

22. Dutch Central Bureau of Statistics. Yearbook of Statistics 2004. Voorburg/Heerlen (Netherlands): Dutch Central Bureau of Statistics; 2004.

23. Smulders PGW, Andries F, Otten F. Hoe denken Nederlanders over hun werk...? Opzet, kwaliteit en eerste resultaten van de TNO Arbeidssituatie Survey. [What do the Dutch think of their work...?: design, quality, and first results of the TNO Work Situation Survey]. Heerhugowaard (Netherlands): Plantijn Casparie; 2001.

24. Dutch Central Bureau of Statistics. Yearbook of Statistics 2003. Voorburg/Heerlen (Netherlands): Dutch Central Bureau of Statistics; 2003. 
25. Bielenski H, Bosch G, Wagner A. Working time preferences in sixteen European countries. Dublin: European Foundation for the Improvement of Living and Working Conditions; 2002.

26. Schaufeli W, van Dierendonck D. UBOS Utrechtse Burnout Schaal: Handleiding [Manual of the Utrecht Burnout Scale]. Lisse (Netherlands): Swets \& Zeitlinger; 2000.

27. Schaufeli WB, Salanova M, González-Romá V, Bakker AB. The measurement of engagement and burnout: a two sample confirmatory factor analytic approach. J Happiness Stud. 2002;3:71-92a

28. Karasek RA, Pieper CF, Schwartz JE. Job Content Questionnaire and user's guide: revision 1.1. Los Angeles (CA): University of California, Los Angeles; 1985.

29. Karasek R, Theorell T. Healthy work: stress, productivity, and the reconstruction of working life. New York (NY): Basic Books; 1990.

30. Spector PE. Method variance in organizational research: truth or urban legend? Organ Res Methods. 2006;9(2):221-32.

31. Kompier M. Assessing the psychosocial work environment"subjective" versus "objective" measurement [editorial]. Scand J Work Environ Health. 2005;31(6):405-8.

32. Semmer NK, Grebner S, Elfering A. Beyond self-report: using observational, physiological, and situation-based measures in research on occupational stress. In: Perrewe PL, Ganster
DC, editors. Research in occupational stress and well-being: emotional and physiological processes and positive intervention strategies. Amsterdam (Netherlands): Elsevier; 2004. p 205-63.

33. Taris TW, Kompier M. Challenges in longitudinal designs in occupational health psychology [editorial]. Scand J Work Environ Health. 2003;29(1):1-4.

34. De Lange AH, Taris TW, Kompier MAJ, Houtman ILD, Bongers PM. The relationships between work characteristics and mental health: Examining normal, reversed, and reciprocal relationships in a 4-wave study. Work Stress. 2004;18:14966.

35. Baldwin PJ, Dodd M, Wrate, RW. Young doctors' health, I: how do working conditions affect attitudes, health and performance? Soc Sci Med. 1997;45:35-40.

36. Dembe AE, Erickson JB, Delbos RG, Banks SM. The impact of overtime and long work hours on occupational injuries and illnesses: new evidence from the United States. Occup Environ Med. 2005;62:588-97.

37. Dong X. Long workhours, work scheduling and work-related injuries among construction workers in the United States. Scand J Work Environ Health. 2005;31(5):329-35.

Received for publication: 21 December 2005

\section{Appendix 1}

\section{Descriptive statistics of the study variables ( $\mathrm{N}=2419)$}

\begin{tabular}{|c|c|c|c|c|c|c|c|c|c|c|c|}
\hline & Range & Mean & SD & 1. & 2. & 3. & 4. & 5. & 6. & 7. & 8. \\
\hline 1. Contractual workhours & $0-40$ & 31.7 & 10 & - & & & & & & & \\
\hline 2. Overtime hours & 0-39 & 3.5 & 6 & 0.02 & - & & & & & & \\
\hline 3. Fatigue & $1-7$ & 2.6 & 1.4 & $0.08^{a}$ & $0.04^{b}$ & - & & & & & \\
\hline 4. Work motivation & $1-5$ & 3.4 & 0.8 & $0.15^{a}$ & $0.12^{\mathrm{a}}$ & $-0.31^{a}$ & - & & & & \\
\hline 5. Job demands & $1-4$ & 2.5 & 0.6 & $0.17^{\mathrm{a}}$ & $0.15^{\mathrm{a}}$ & $0.33^{a}$ & $0.15^{\mathrm{a}}$ & - & & & \\
\hline 6. Decision latitude & $1-4$ & 2.9 & 0.6 & $0.19^{a}$ & $0.06^{a}$ & $-0.13^{\mathrm{a}}$ & $0.30^{\mathrm{a}}$ & $0.07^{a}$ & - & & \\
\hline 7. Job variety & $1-4$ & 2.9 & 0.6 & $0.32^{\mathrm{a}}$ & $0.12^{\mathrm{a}}$ & -0.01 & $0.51^{\mathrm{a}}$ & $0.26^{\mathrm{a}}$ & $0.31^{\mathrm{a}}$ & - & \\
\hline 8. Age & $15-67$ & 39.7 & 11.8 & $0.32^{\mathrm{a}}$ & $-0.04^{b}$ & 0.01 & $0.22^{\mathrm{a}}$ & $0.13^{\mathrm{a}}$ & $0.16^{\mathrm{a}}$ & $0.20^{\mathrm{a}}$ & - \\
\hline 9. Gender c & - & - & - & $-0.46^{a}$ & 0.01 & 0.02 & -0.03 & 0.03 & $-0.05^{b}$ & $-0.10^{a}$ & $-0.28^{a}$ \\
\hline
\end{tabular}

a $P<0.01$.

${ }^{b} \mathrm{P}<0.05$.

c $1=$ male, 2 = female. 